\title{
Estimation of Ground Structure at USM using Microtremor Observation Technique
}

\author{
Kang Chin Tan ${ }^{*}$, Yi Ben Cheah ${ }^{1}$ and Tze Liang Lau ${ }^{1}$ \\ ${ }^{1}$ School of Civil Engineering, Universiti Sains Malaysia, Engineering Campus, 14300 Nibong Tebal, \\ Penang, Malaysia
}

\begin{abstract}
Determination of ground structure is important for seismic hazard analysis and earthquake design of structures. Different types of ground structure at site, depending on its profile of shear-wave velocity, will amplify seismic wave at different extents. Therefore, structures should be designed accordingly to withstand the expected surface ground motion considering seismic site amplification. Microtremor observations were conducted in this study due to its simplicity, less field effort and economy. Field measurement was carried out at two sites at Universiti Sains Malaysia Engineering Campus where the actual soil profiles were known from the existing borelog data. Two sizes of circular array formed by three threecomponent velocity sensors along the circumference of circle and a threecomponent velocity sensor at the center for each array were performed. The recorded data were analysed using Spatial Autocorrelation (SPAC) method. Shear wave velocity profile for the site was then estimated through inversion of phase velocity. To produce convincing estimation of ground structure, the horizontal to vertical $(\mathrm{H} / \mathrm{V})$ spectra at the center of the circular array was compared with the computed ellipticity of the fundamental mode of Rayleigh wave. The obtained results were also compared with the borelog data. The accuracy for the estimation of ground structure based on various microtremor array sizes and analysis techniques was assessed.
\end{abstract}

\section{Introduction}

Local site amplification is one of the key parameters in earthquake design of structures as the seismic ground motion can be significantly amplified by near-surface soil deposits. Depending on the local geological condition, the arriving seismic waves can manifest to varied degree of shaking intensity and amplitude.

Shear-wave velocity profile of the soil structure and its geometry are the key parameters that control local site amplification. Traditionally, the shear-wave velocity of the soil formation at site is determined by seismic measurements in boreholes by using the downhole, crosshole or suspension logging methods. This however presents practical difficulties in the cases where the sites of interest are within the urban areas. The time and manpower required for such geophysical measurements are also high and inhibitive on a project's cost expenditure.

\footnotetext{
* Corresponding author: kangchin91@gmail.com
} 
The aforementioned difficulties can be overcome by microtremor measurement, where the ambient ground vibration is recorded by sensors deployed on the ground without the need of intrusive or destructive soil test. Microtremor observation has been applied by researchers to recognise the properties of surface waves, and thereby to infer the profile of subsurface soil structures.

The Spatial Autocorrelation Method (SPAC) was first pioneered by Aki [1] and further developed by Henstridge [2] and Okada [3] to estimate shear-wave velocity profile through the array measurement of microtremors. In this method, the phase velocity of the surface waves is extracted from the observed microtremors in the form of dispersion curve. The 1-D distribution of shear wave velocity is subsequently computed via inversion of the dispersion curve. The SPAC method was assessed and adopted in various studies [4-8] and was collectively found to show reliability.

The H/V technique which evaluate the horizontal-to-vertical spectral ratios of the microtremors was popularised by Nakamura [9] to estimate the site effects. This technique was further applied in estimating the fundamental periods [10-11] and relative amplification factors of the sites (e.g., Lermo and Chavez-Garcia [12]; Konno and Ohmachi [13]). The peak of horizontal-to-vertical spectral ratios were empirically found to match the Rayleigh wave's ellipticity of the sites with layered medium [14-16].

In the present paper, both Spatial Autocorrelation method (SPAC) and H/V technique were used in the effort of estimating the shear wave velocity soil profiles based on the microtremor recordings. The results obtained are compared with the available borelog data.

\section{Microtremor field measurement}

Microtremor field measurement was conducted at two sites in the Engineering Campus of Universiti Sains Malaysia where the actual soil profiles near the sites were known based on existing borelog data. The measured sites are as shown in Figure 1. At both sites, the array measurements consisted of circular array formed by three numbers of three-component velocity sensors along the circumference of the circle and one three-component velocity sensor at the circle center. The formation of the array measurement is as shown in Figure 2. Two different array sizes of $1 \mathrm{~m}$ radius and $10 \mathrm{~m}$ radius were arranged for observation at each respective site.

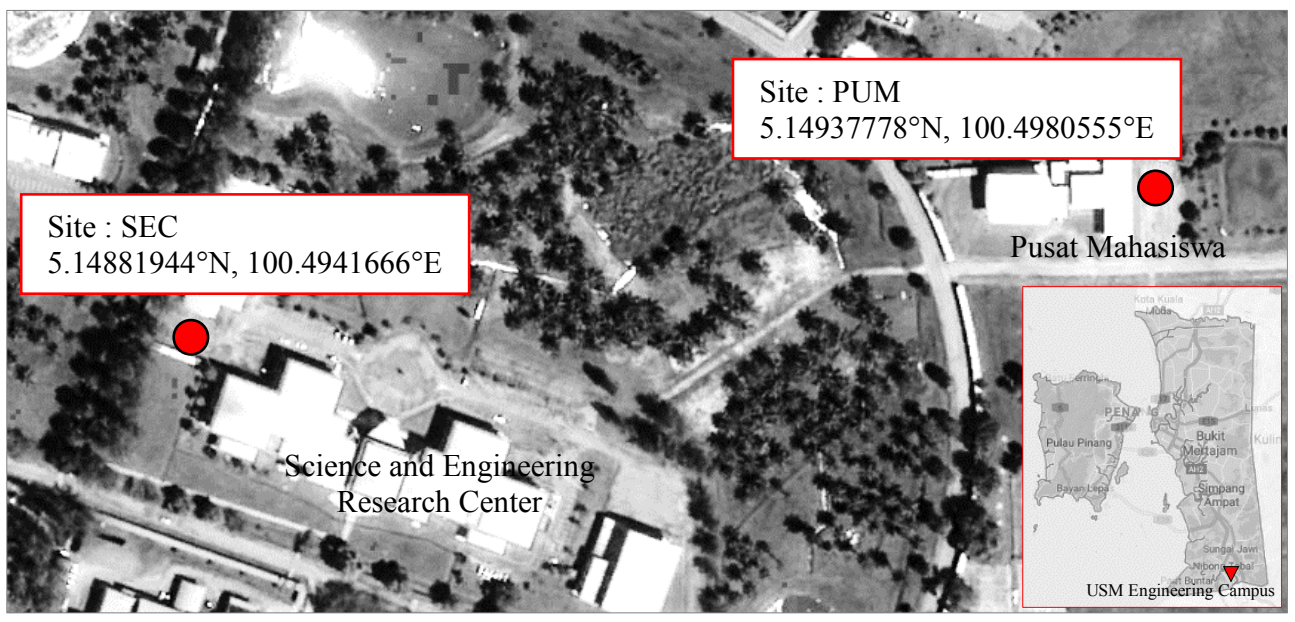

Fig. 1. Locations of microtremor measurement at Engineering Campus, Universiti Sains Malaysia. 


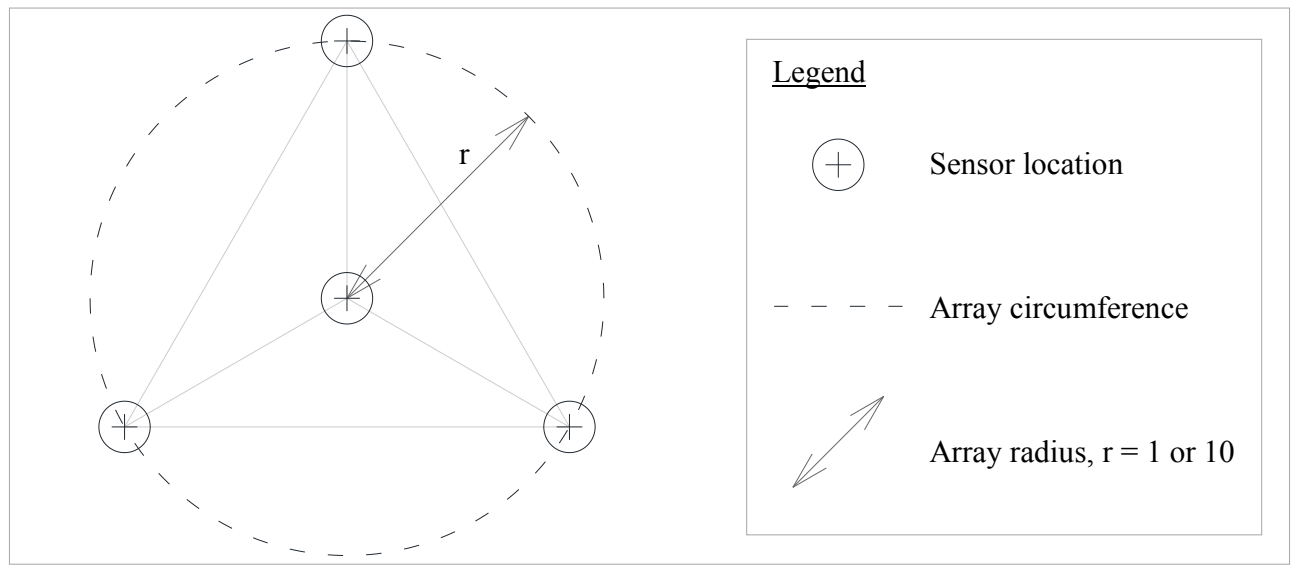

Fig. 2. Microtremor array arrangement for array radius of $1 \mathrm{~m}$ and $10 \mathrm{~m}$ respectively.

\section{Data processing and analysis}

The observed field data was dissected into segments of 30 seconds signal length. Segments disturbed by the spikes from cultural or industry noises are discarded. The filtered signal segments were then used as the raw data in the evaluation of SPAC method to compute the wavefield dispersion curve. As the array formation resembled a shape of equilateral triangle with three sensors at the outer vertices and one sensor at the center, the observed azimuthalaverage of the spatial auto-correlation coefficient $\rho(\omega, r)$ can be calculated as:

$$
\rho(\omega, r)=\frac{1}{3} \sum_{j=1}^{3} \frac{\operatorname{Re}\left(S_{0 j}(\omega)\right)}{S_{00}(\omega) S_{j j}(\omega)},
$$

where $\omega$ is the angular frequency, $r$ is the array radius, $S_{j j}(\omega)$ is the power spectra of the vertical component of measured microtremors at position $j(j=0,1,2,3$ in which position 0 is the array center and positions $1,2,3$ are at the array vertices), and $S_{0 j}(\omega)$ is the cross spectra of the vertical component records between position $j$ and 0 .

Fundamentally, the azimuthal-average of spatial autocorrelation coefficient $\rho(\omega, r)$ is defined as:

$$
\rho(\omega, r)=J_{0}(k r)=J_{0}\left(\frac{\omega r}{c(\omega)}\right)=J_{0}\left(\frac{2 \pi f r}{V(f)}\right),
$$

where $J_{0}$ is the Bessel function of the first kind of zero order, $k$ is the spatial wave number at frequency $f, r$ is the array radius, $\omega$ is the angular frequency, $c(\omega)$ indicates the phase velocity of surface wave, and $V(f)$ is the shear wave velocity dispersion function of a layered soil $[1,17]$. Hence, by obtaining the spatial autocorrelation coefficient, the dispersion curve can be computed and the shear wave velocity of the subsurface layers can be evaluated.

Additionally, the vertical and horizontal components of the microtremor wavefield were measured by the sensor located at the array center. Such records were used to compute the horizontal to vertical spectra ratio $(H / V)$ by: 


$$
(H / V)=\sqrt{\frac{S_{N S}^{2}+S_{E W}^{2}}{\left(2{S_{U D}}^{2}\right)}},
$$

where $S_{N S}$ is the Fourier amplitude in the horizontal north-south direction, $S_{E W}$ is the Fourier amplitude in the horizontal east-west direction, and $S_{U D}$ is the Fourier amplitude in the vertical up-down direction. The horizontal to vertical spectra ratio is compared with the theoretical Rayleigh-wave ellipticity generated from the soil structure evaluated from SPAC method, to further confirm the interpretation of microtremor observations.

\section{Results and discussion}

Through the SPAC method, the microtremor array measurement yields phase velocity as a function of frequency, also known as the observed dispersion curve. In Figure 3 and Figure 4 , the dispersion curves obtained with varied array sizes are shown for site SEC and PUM respectively.

For each plot in Figure 3 (Site: SEC) and Figure 4 (Site: PUM), the red and black lines resemble the dispersion curves computed based on the observed microtremor wavefield. The red line is derived from the ground motion cross spectra between the array center and array vertices; and the black line among the outer vertices. The coloured dash line is the theoretical dispersion curve generated based on a layered soil construct, each chosen among a vast set of soil models to best fit the average converged slope of the observed dispersion curves. In other words, the inversion of this theoretical line will produce the equivalent soil structure.

(a)

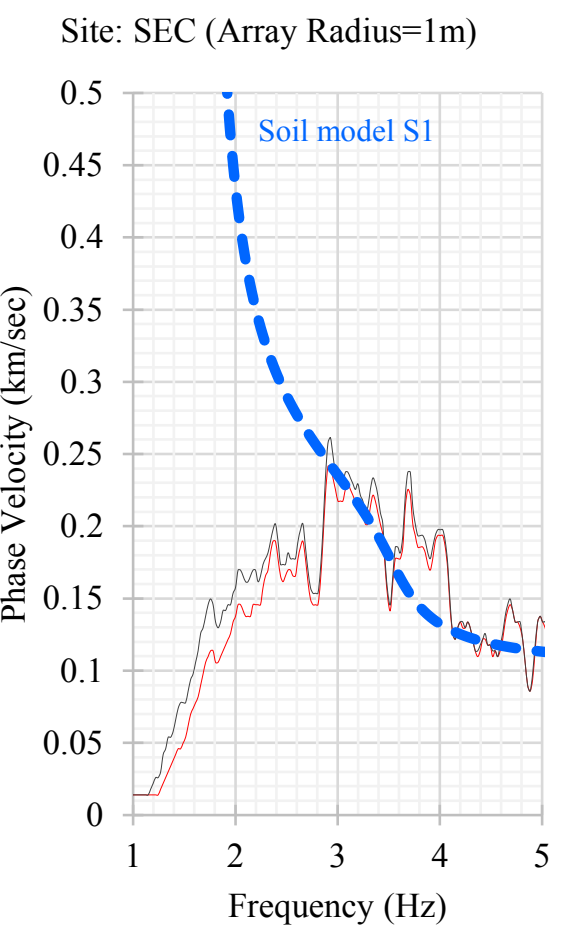

(b)

Site: SEC (Array Radius=10m)

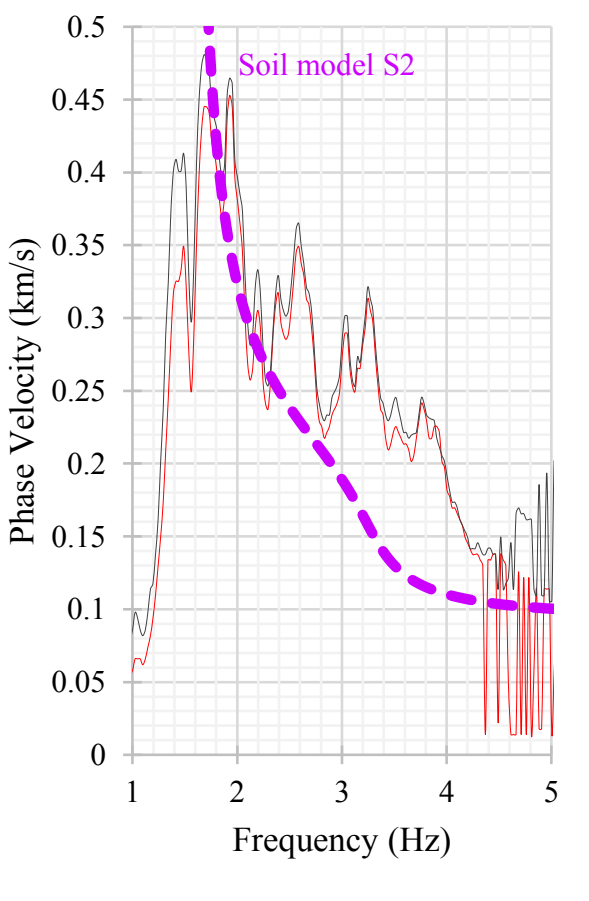

Fig. 3. Dispersion curves based on array radius of $1 \mathrm{~m}$ (Fig. 3a) and $10 \mathrm{~m}$ (Fig. 3b), at site SEC. 
(a)

Site: PUM (Array Radius $=1 \mathrm{~m})$

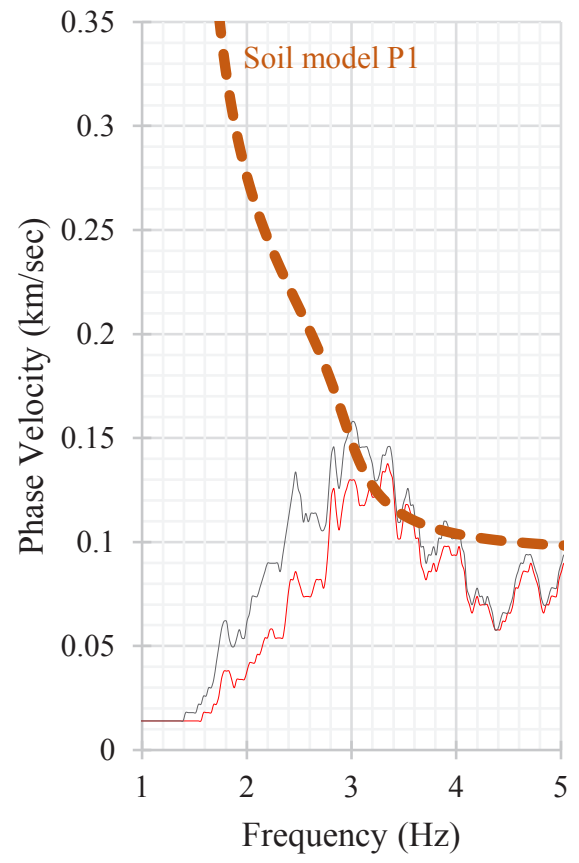

(b)

Site: PUM (Array Radius=10m)

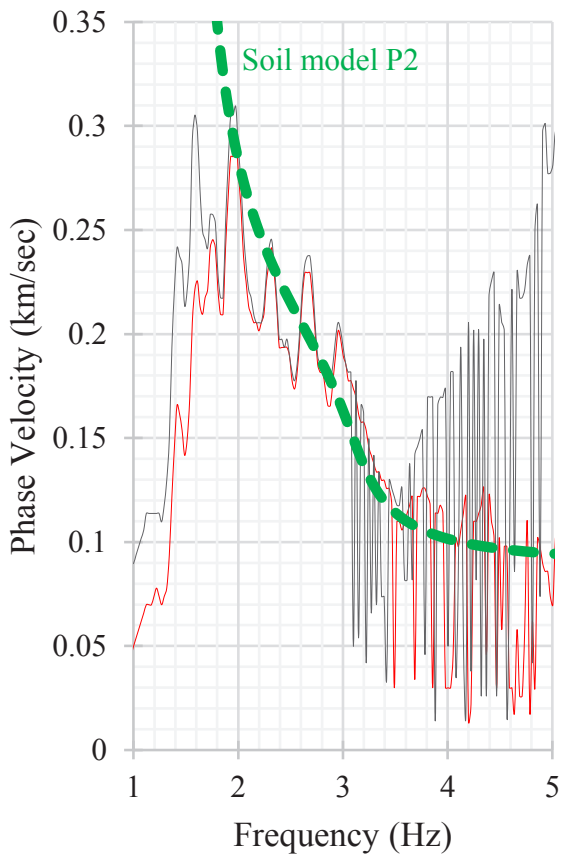

Fig. 4. Dispersion curves based on array radius of $1 \mathrm{~m}$ (Fig. 4a) and 10m (Fig. 4b), at site PUM.

The soil models which their theoretical dispersion curves can best match the observed dispersion curves are charted with the $\mathrm{N}$-values of the standard penetration test $\left(\mathrm{N}_{\mathrm{SPT}}\right)$ obtained from borelog in Figure 5 (Site: SEC) and Figure 6 (Site: PUM). Different categories of ground types in accordance to Eurocode 8 are demarcated in both figures to validate the computed soil models with the available borelog data.

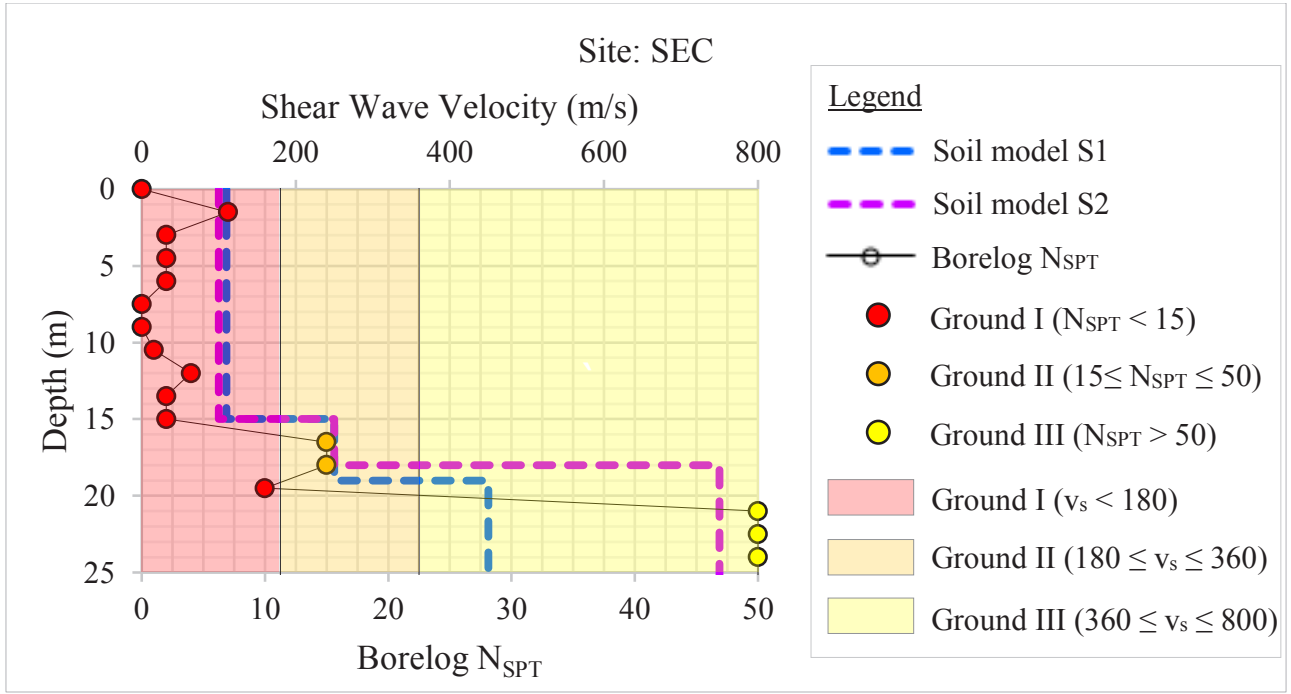

Fig. 5. Shear wave velocity profiles of computed soil models at SEC and NSPT from borelog. 


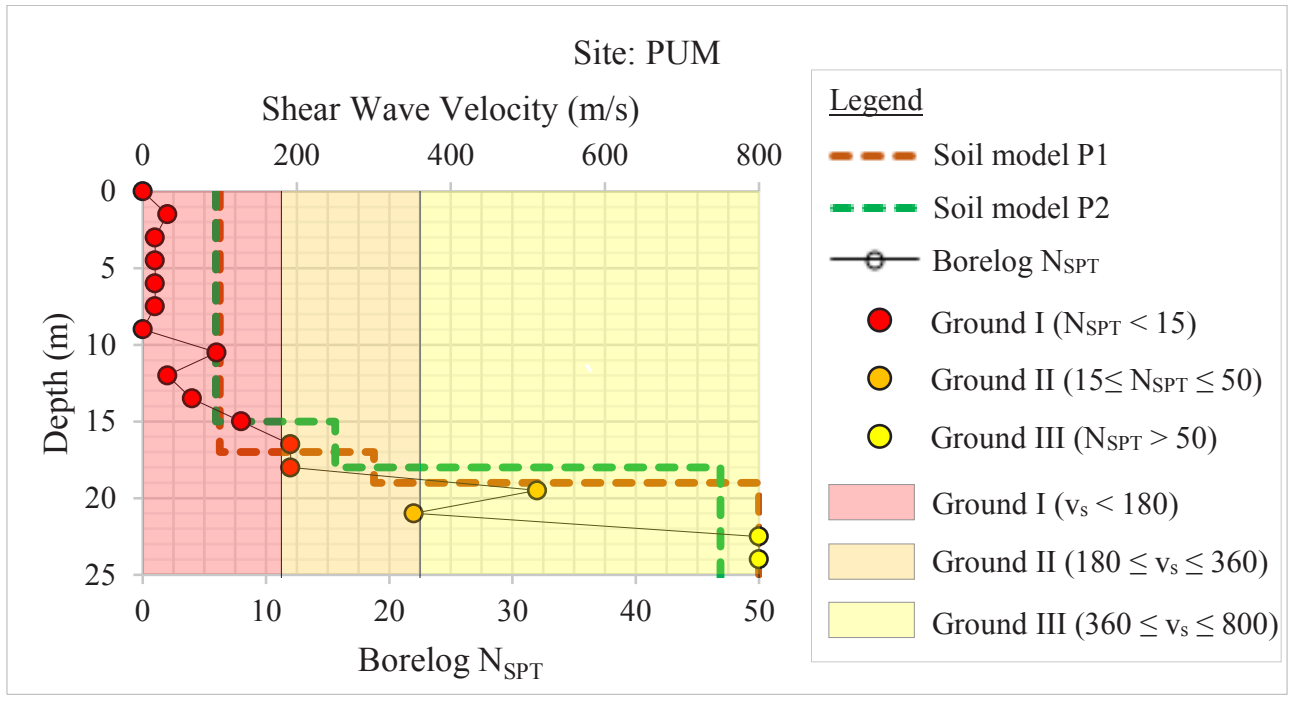

Fig. 6. Shear wave velocity profiles of computed soil models at PUM and N $\mathrm{SPT}$ from borelog.

In Figure 5 and Figure 6 above, the shear wave velocity profiles of all four soil models evaluated from SPAC method are plotted as dashed coloured lines. To compare the computed soil models with borelog, we refer to Clause 3.1.2, Table 3.1 of Eurocode 8 (EC8) [18] where the ground types are categorised by shear wave velocity $\left(\mathrm{v}_{\mathrm{s}}\right)$ and $\mathrm{N}_{\mathrm{SPT}}$. We firstly categorise the ground types of the soil models according to EC8's reference on shear wave velocity, where the $\mathrm{v}_{\mathrm{s}}$ of Ground I (red zone) is lesser than $180 \mathrm{~m} / \mathrm{s}$, $\mathrm{v}_{\mathrm{s}}$ of Ground II (orange zone) is greater than $180 \mathrm{~m} / \mathrm{s}$ and lesser than $360 \mathrm{~m} / \mathrm{s}$, while the $\mathrm{v}_{\mathrm{s}}$ of Ground III (yellow zone) is greater than $360 \mathrm{~m} / \mathrm{s}$ and lesser than $800 \mathrm{~m} / \mathrm{s}$. By this means, the shear wave velocity profiles of the computed soil models are characterised by ground types. We can then make an obvious comparison with the collateral plot of borelog $\mathrm{N}_{\mathrm{SPT}}$, where Ground I (red dot) has $\mathrm{N}_{\mathrm{SPT}}$ lesser than 15, Ground II (orange dot) has $\mathrm{N}_{\mathrm{SPT}}$ between 15 and 50, while Ground III (yellow dot) has $\mathrm{N}_{\mathrm{SPT}}$ greater than 50 .

For an example, the first $15 \mathrm{~m}$ thick layer of the computed soil models at site SEC has the shear wave velocity $100 \mathrm{~m} / \mathrm{s}-110 \mathrm{~m} / \mathrm{s}$ and is characterised as type Ground I with its position in the chart's red zone. This coincides with the borelog data, where the red dots of N NPT plot also represent a $15 \mathrm{~m}$ thick Ground I soil. Similarities are observed among the shear wave velocity profiles of the computed soil models at SEC and PUM. The computed soil profiles of both sites are shown in Table 1 .

Table 1. Subsurface structures of the computed models at SEC and PUM.

\begin{tabular}{|c|c|c|c|c|}
\hline \multirow{2}{*}{ Site: SEC } & \multicolumn{2}{|c|}{ Soil model S1 } & \multicolumn{2}{c|}{ Soil model S2 } \\
\cline { 2 - 5 } & Thickness $(\mathrm{m})$ & $\mathrm{v}_{\mathrm{s}}(\mathrm{m} / \mathrm{s})$ & Thickness $(\mathrm{m})$ & $\mathrm{v}_{\mathrm{s}}(\mathrm{m} / \mathrm{s})$ \\
\hline Layer 1 & 15 & 110 & 15 & 100 \\
\hline Layer 2 & 4 & 250 & 3 & 250 \\
\hline Layer 3 & 15 & 450 & 10 & 750 \\
\hline \multirow{2}{*}{ Site: PUM } & \multicolumn{2}{|c|}{ Soil model P1 } & \multicolumn{2}{c|}{ Soil model P2 } \\
\cline { 2 - 5 } & Thickness $(\mathrm{m})$ & $\mathrm{V}_{\mathrm{s}}(\mathrm{m} / \mathrm{s})$ & Thickness $(\mathrm{m})$ & $\mathrm{V}_{\mathrm{s}}(\mathrm{m} / \mathrm{s})$ \\
\hline Layer 1 & 17 & 100 & 15 & 95 \\
\hline Layer 2 & 2 & 300 & 3 & 250 \\
\hline Layer 3 & 7 & 800 & 10 & 750 \\
\hline
\end{tabular}


Using the parameters of the soil models evaluated from SPAC method above, the theoretical curve of Rayleigh wave ellipticity of each site is calculated and compared with the plot of horizontal-to-vertical spectral ratios of the recorded microtremors, as shown in Figure 7 and Figure 8. Both figures show that the fundamental frequency of the ellipticity curves (coloured dash lines) closely coincide the fundamental frequency of the H/V spectral ratios (black lines). This contributes to the validation of the soil profiles estimated from the SPAC method.

(a)

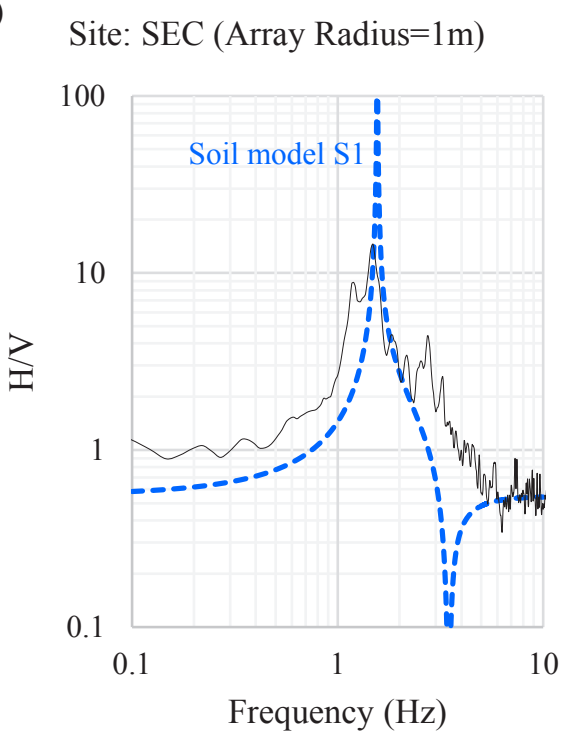

(b)

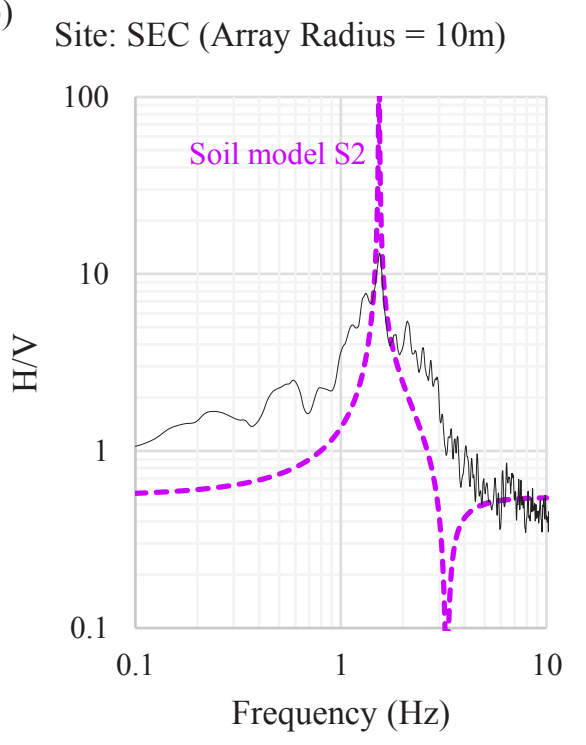

Fig. 7. H/V spectra ratio of microtremors of array radius $1 \mathrm{~m}$ (Fig. 8a) and 10m (Fig. 8b) at SEC.

(a)

Site: PUM (Array Radius=1m)

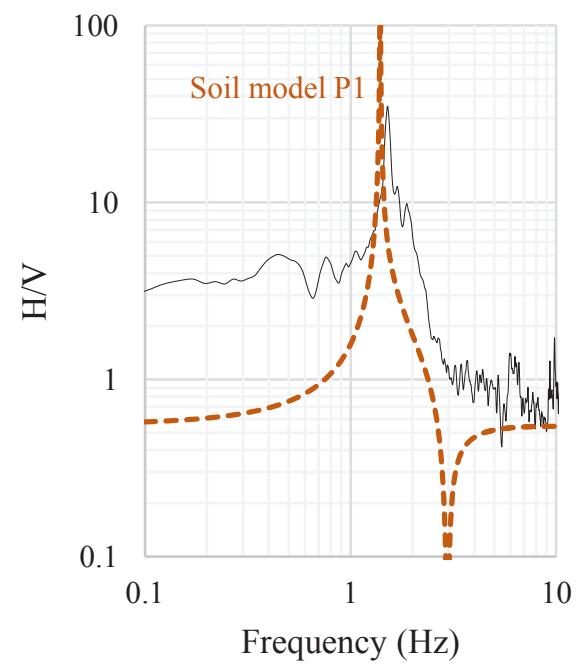

(b)

Site: PUM (Array Radius=10m)

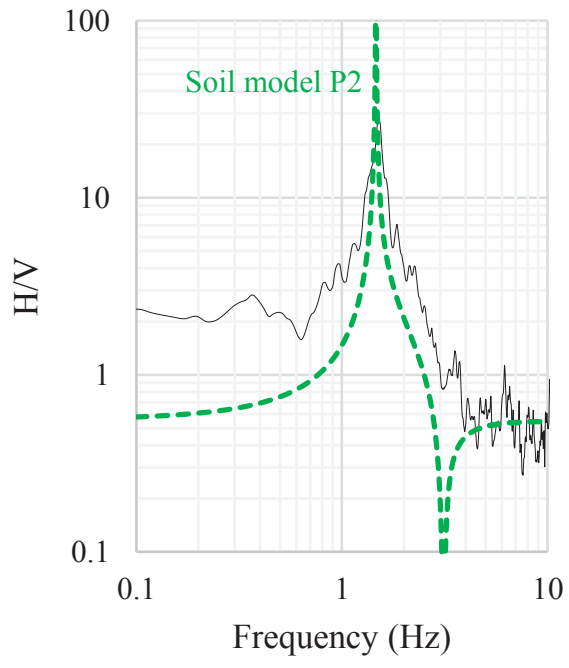

Fig. 8. H/V spectra ratio of microtremors of array radius $1 \mathrm{~m}$ (Fig. 9a) and 10m (Fig. 9b) at PUM. 
Two different array sizes of microtremor measurement are conducted in our study with an attempt to assess the effect of array sizes on the accuracy of ground structure estimation. As shown in Figure 5 and Figure. 6, the difference between the subsurface structures evaluated from array radius of $1 \mathrm{~m}$ and $10 \mathrm{~m}$ seems to mainly occur in the deeper layers, at depth beyond $18 \mathrm{~m}$. This could be attributed to the loss of resolution at greater depths by the small radius array or the significant presence of lateral subsurface deviations in the large radius array. Another noticeable difference between $1 \mathrm{~m}$ and $10 \mathrm{~m}$ radius array is the frequency range of the dispersion curve calculated from microtremor measurement. The segments of frequency range to calculate dispersion curve are decided from the array radius, for example, range of $3-5 \mathrm{~Hz}$ is decided from $1 \mathrm{~m}$ array, whereas $2-3 \mathrm{~Hz}$ from $10 \mathrm{~m}$ array, and those phase velocities are combined when the inversion technique is adopted.

\section{Conclusions}

Microtremor array observation was carried out at two sites at the Engineering Campus of Universiti Sains Malaysia. Two array sizes of $1 \mathrm{~m}$ and $10 \mathrm{~m}$ were used at each site. The recorded microtremor wavefield was processed by the SPAC method, by which the resolved dispersion curve can be used to determine the shear wave velocity profiles of the subsurface structure. A vast set of theoretical dispersion curves generated from iterated soil models were taken to match the dispersion curves computed from microtremor observation. The soil model that can best match the average converged slope of the observed dispersion curves is deemed the model obtained from the inversion method.

Soil models obtained from the SPAC method were compared with the borelog data at both measured sites and achieved good agreement. The soil models were also used to generate the theoretical curves of Rayleigh wave ellipticity, which the fundamental peak frequencies were found to closely match the fundamental frequency of the observed $\mathrm{H} / \mathrm{V}$ spectra ratios. This suggests that the soil profiles computed from SPAC method can benefit from the check on Rayleigh wave ellipticity curves. Our findings suggest microtremor observations can be one of the viable solutions in determining subsurface structure for seismic microzonation and earthquake design of structures in a region.

The authors would like to express their sincere gratitude to JICA AUN/SEED-Net for funding this research through Collaborative Research Program for Common Regional Issues (CRC). Special appreciation also goes to Professor Hitoshi Morikawa for providing the analysis program and guidance.

\section{References}

1. K. Aki, Bull. Earthq. Res. Inst., 35, 415-456 (1957)

2. J.D. Henstridge, Geophysics, 44, 179-184 (1979)

3. H. Okada, A new method of underground structure estimation using microtremors (Hokkaido University, Japan, 1997)

4. J.N. Louie, Bull. Seismol. Soc. Am. 91, 347-364 (2001)

5. M. Wathelet, D. Johnmans, M. Ohrnberger, Near Surf. Geophys. 2, 211-221 (2004)

6. A. Garcia-Jerez, M. Navarro, F. Alcala, F. Luzon, J. Perez-Ruiz, T. Enomoto, F. Vidal, E. Ocana, Soil Dyn. Earthq. Eng. 27, 907-919 (2007)

7. C.M. Lin, T.M. Chang, Y.C. Huang, H.J. Chiang, C.H. Kuo, K.L. Wen, Terr. Atmos. Ocean. Sci. 20, 299-308 (2009)

8. C.F. Wu, H.C. Huang, Taiwan, Bull. Seismol. Soc. Am. 103, 1154-1164 (2013)

9. Y. Nakamura, Railway Tech. Res. Inst. 30, 25-33 (1989) 
10. E. Field, K. Jacob, Geophys. Res. Lett. 20, 2925-2928 (1993)

11. T. Ohmachi, K. Konno, T. Endoh, and T. Toshinawa, J. JSCE, 489, I-27, 251-261 (1994)

12. J. Lermo, F.J. Chavez-Garcia, Bull. Seismol. Soc. Am. 83, 1574-1594 (1993)

13. K. Konno and T. Ohmachi, J. JSCE, 525, I-33, 247-259 (1995)

14. C. Lachet, and P.-Y. Bard, J. Phys. Earth, 42, 377-397 (1994)

15. K. Tokimatsu, Earthquake Geotechnical Engineering (Balkema, Rotterdam, 1997)

16. F. Scherbaum, K.G. Hinzen and M. Ohrnberger, Geophys. J. Int., 152, 597-612 (2003)

17. H. Okada, The microtremor survey method (American Geophysical Union, Washington, 2003)

18. EN 1998-1:2004: Design of structures for earthquake resistance: Part 1: General rules, seismic actions and rules for buildings (European Committee for Standardization, 2004) 